\title{
Las ciencias sociales sistémicas y la pandemia del coronavirus
}

\section{Systemic social sciences and the coronavirus pandemic}

Marcelo Arnold-Cathalifaud (marnold@uchile.cl) Departamento de Antropología, Universidad de Chile (Santiago, Chile) https://orcid.org/0000-0003-1649-8512

Sergio Pignuoli-Ocampo (spignuoli@hotmail.com) CONICET, Universidad de Buenos Aires (Buenos Aires, Argentina) http://orcid.org/0000-0002-9918-0931

Daniela Thumala-Dockendorff (dthumala@uchile.cl) Departamento de Psicología, Universidad de Chile (Santiago, Chile) https://orcid.org/0000-0003-0392-7031

\begin{abstract}
Given the multiplicity of perspectives that accompany the observation of the current pandemic, becomes relevant to identify those that achieve the greatest resonance. Thus, it is observed how citizens and decision makers have increased their demands for valid information by applying rationality, methods, and procedures of science in an exponential manner. In this paper we develop a synthetic set of selected guidelines on how the current pandemic is approached from systemic social sciences, and then present some of their proposals regarding the conditions, at the organizational level, which could enable the achievement of the levels of dialogue and cooperation required to address the current pandemic.
\end{abstract}

Key words: Covid 19, social systems theory, risk, organizations, institutional design.

\section{Resumen}

Dada la multiplicidad de planos que acompañan a las observaciones de la actual pandemia, importa identificar aquellas que alcanzan una mayor resonancia. Así, observamos cómo los ciudadanos y los agentes de decisión han incrementado sus demandas de informaciones validadas por medio de la aplicación de la racionalidad, los métodos y los procedimientos de la ciencia de manera exponencial. En este trabajo desarrollamos en forma sintética un conjunto seleccionado de lineamientos sobre cómo se aborda la actual pandemia desde las ciencias sociales sistémicas, para luego exponer algunas de sus propuestas respecto a las condiciones, a nivel organizacional, las cuales podrían permitir alcanzar los niveles de diálogo y cooperación requeridos para enfrentar la pandemia actual.

Palabras clave: Covid 19, teoría de sistemas sociales, riesgo, organizaciones, diseño institucional. 


\section{Introducción}

Gobiernos, organizaciones y colectivos de diverso tipo han focalizado su atención en una entidad imperceptible a simple vista, que los distintos medios han notificado como virus o agente patógeno "SARS-CoV-2", causante de la enfermedad "COVID-19". A partir de ello se han elaborado múltiples posibilidades de comprensión y su comunicación ha seguido distintos rumbos.

Como no existe una forma única de comprender la pandemia y sus múltiples efectos asociados, importa identificar aquellas que alcanzan una mayor resonancia. Así, observamos cómo los ciudadanos y los agentes de decisión han incrementado de manera exponencial sus demandas de informaciones validadas por medio de la aplicación de la racionalidad, los métodos y los procedimientos de la ciencia. Si bien estos procedimientos no garantizan certezas, sino nuevas preguntas, en general, se prefiere correr riesgos desde conocimientos fundados en ese tipo de criterios. Esto es ciertamente contingente, pero no es para nada inmotivado, ya que responde a los resultados alcanzados por las aplicaciones de la ciencia en crisis epidémicas anteriores y equivalentes. A modo de ejemplo puede mencionarse el confinamiento de la epidemia de poliomielitis en los años cincuenta o las vacunas contra la gripe que se actualizan anualmente frente a la circulación de cepas mutadas de virus influenza. También se toman en consideración los casos de acción exitosa en materia de tratamiento para pacientes $\mathrm{VIH}$ positivo (recordemos que el $\mathrm{VIH} / \mathrm{SIDA}$ no ha perdido el rango de pandemia y que más de 32 millones de personas fallecieron por su causa contabilizados hasta 2019) o frente a los brotes de sarampión en Norteamérica y de ébola en África. Así, la ciencia ha mostrado capacidad de respuesta y ha convertido sus recursos en soluciones sanitarias.

Dada la multiplicidad de planos que acompañan a las observaciones de la actual pandemia, nos interesa destacar que cuando las disciplinas que componen el sistema científico buscan sobrepasar la casuística, añadiendo a sus producciones una comprensión teórica, optimizan sus aportes con teorías que pueden integrar coherentemente lo que se conoce con lo que se va conociendo y, desde allí, avanzar con preguntas renovadas hacia nuevas búsquedas. En ello radica uno de los aportes que ofrece la incorporación de las teorías sistémicas a la racionalidad científica. A través de ellas, las ciencias sociales pueden contribuir a mejorar los afrontamientos a la actual crisis sanitaria, por ejemplo, colocando en la discusión una caracterización más actualizada de la complejidad de la sociedad contemporánea para ofrecer, desde ese punto, recomendaciones derivadas de ese entendimiento.

A continuación, desarrollaremos en forma sintética un conjunto seleccionado de lineamientos sobre cómo se aborda la actual pandemia desde las ciencias sociales sistémicas, para luego exponer algunas de sus propuestas respecto a las condiciones, a nivel organizacional, que podrían permitir alcanzar los niveles de diálogo y cooperación requeridos para enfrentar la pandemia actual. Previamente se expondrá el caso a fin de cumplir con el requisito de colocar el objeto del análisis en relación con una perspectiva de observación, o en términos de Maturana: "presentación de la experiencia (fenómenos) que ha de explicarse en términos de lo que un observador tipo tiene que hacer en su dominio de experiencias (práctica de vida) para experimentarla" (Maturana 2009:74). 


\section{Exposición del caso}

La declaración del brote de la enfermedad por coronavirus, de acuerdo con la temprana denominación que le diera la OMS, es un fenómeno datado hacia fines del año 2019. Esto no ha obstado para que la investigación científica haya producido y acumulado ingentes volúmenes de conocimiento sobre el mismo durante 2020. La virología ha denominado al nuevo coronavirus SARSCoV-2 (Severe Acute Respiratory Syndrome Coronavirus 2) y determinado sus principales rasgos en materia de composición, replicación y filogénesis, emparentándolo con el SARS-CoV, cuyo brote epidémico data de 2002: "[I]n terms of taxonomy, SARS-CoV-2 is (just) another virus in the species severe acute respiratory syndrome-related coronavirus. In this respect, the discovery of this virus differs considerably from the description of the two other zoonotic coronaviruses, SARS-CoV and MERS-CoV, introduced to humans in the 21st century" (Gorbalenya. Severe acute respiratory syndrome-related coronavirus).

Desde la infectología se determinó tempranamente que el SARS-CoV-2 es el agente patogénico causante de una pulmonía atípica, cuyos cuadros clínicos más graves pueden conducir a la muerte. La inmunología (cuyo papel en la discusión ha crecido a la par del aumento de número de pacientes recuperados) ha establecido que, dada la alta transmisibilidad del virus, el umbral crítico de inmunidad colectiva (la -anhelada- protección de rebaño) recién se alcanzaría cuando el 60-70\% de la población haya sido infectada por SARS-CoV-2 (Kwok. Herd immunity).

En tanto, la epidemiología ha modelado diversos escenarios posibles del progreso, tanto del contagio como del desarrollo de la enfermedad, en base a escenarios de acción o inacción sanitaria señalando, últimamente, la probabilidad de nuevas olas de contagio con distintas curvas: "Whichever scenario the pandemic follows (assuming at least some level of ongoing mitigation measures), we must be prepared for at least another 18 to 24 months of significant COVID-19 activity, with hot spots popping up periodically in diverse geographic areas" (CIDRAP. COVID 19).

Si bien estos conocimientos entregan información sobre los rasgos microbiológicos y poblacionales del fenómeno en cuestión, dejan constancia del amplio margen de indeterminación que los rige como tales, como conocimientos. Así, las disciplinas mencionadas asumen que hay muchos aspectos desconocidos del fenómeno y que sus avances, no necesariamente clínicos, demandan mucho de lo que la urgencia recorta: tiempo. Asimismo, algunos de los avances más firmes en el conocimiento del fenómeno reconocen no solo la existencia de baches o gaps en el cuerpo de conocimiento supuesto y resultante, sino también que para franquearlos y "ganar tiempo" se apeló a informaciones puestas a disposición por la investigación del SARS-CoV, asumiendo así que, en rigor, parte de los supuestos requieren evidencia específica. En este sentido, los aspectos ya determinados del fenómeno, al igual que los indeterminados, son productos del mismo curso de la investigación científica en materia virológica, infectológica, inmunológica y epidemiológica. Es decir que, de los progresos del conocimiento científico, surgen nuevos niveles y formas de incertidumbres científicas. Específicamente, no puede preverse con la certeza requerida y ansiada por la opinión pública, cuáles serán todos los efectos de la pandemia en la población, y tampoco cómo ellos variarán de acuerdo con condiciones que están cambiando a cada momento.

Para observar la cambiante dinámica de la pandemia (y sin desconocer los conocimientos que se están produciendo y acumulando en virología, inmunología y epidemiología sobre SARS-CoV-2 y COVID-19), abordaremos su elaboración social a través de la distinción sistémica riesgo/peligro. Un 
rasgo destacado en esta coyuntura es la recuperación de la tesis desarrollada por Ulrich Beck en su libro sobre la sociología del riesgo, el cual, sin duda, se ha transformado en una referencia ineludible dentro del contexto que atravesamos. Sin embargo, por esas mismas razones, y dada la relevancia de las distinciones trazadas por el aludido sociólogo, encontramos apropiado volver a una fuente más consistente con la teoría sistémica, como es la elaboración bajo la forma de riesgo y peligro planteada por Niklas Luhmann (¿Puede la sociedad moderna evitar los peligros ecológicos?).

Luhmann advirtió e insistió en el hecho de que la elaboración de amenazas en la sociedad no es un simple momento estático, latente o efectivo de publicidad de alarmas, más bien se trata de una dinámica alternante de riesgos, pero también de peligros, y que la forma de las amenazas (siendo el COVID-19 actualmente un caso de ellas) oscila entre los valores que adopta y abandona en el curso de su construcción alarmante para la sociedad. En este sentido, los términos de la forma riesgo/peligro facilitan la observación continua del sentido de las alarmas, las protestas, las catástrofes y los futuros que se visualizan en la sociedad. Según esta conceptualización, tanto el riesgo como el peligro son términos que designan el encuadre social de una amenaza percibida, por ejemplo, contraer COVID-19, pero, mientras el peligro atribuye esa amenaza a sucesos del entorno, como contagiarse inesperadamente, el riesgo la atribuye a las acciones del sistema, por ejemplo, descuidar las medidas de protección.

Desde la perspectiva sistémica, SARS-CoV-2 y COVID-19 han sido conformados comunicativamente en la sociedad y se observa en su desarrollo una dinámica de tres formas sociales que se han sucedido dinámicamente, no sin momentos de convivencia temporal entre ellas. Situamos la primera forma en el periodo comprendido entre la declaración del brote como "emergencia de salud pública de importancia internacional" por la OMS el 30 de enero de 2020, es decir, antes de que fuera declarada "pandemia" por el mismo organismo el 11 de marzo de 2020: "Actualmente hay 98 casos confirmados en 18 países fuera de China, incluidos 8 por transmisión de persona a persona en cuatro países: Alemania, el Japón, Viet Nam y los Estados Unidos de América. Hasta el momento no se ha notificado ninguna muerte fuera de China, algo por lo que todos debemos estar agradecidos. Aunque esas cifras todavía son relativamente pequeñas en comparación con el número de casos en China, debemos actuar de forma inmediata y coordinada para limitar la propagación del brote. La mayoría de los casos fuera de China habían viajado a Wuhan, o venían de esa ciudad. Desconocemos el tipo de daños que el virus podría ocasionar si se propagase en un país con un sistema de salud menos robusto. Debemos actuar inmediatamente para ayudar a los países a prepararse ante esa posibilidad. Por todas esas razones, declaro que el brote mundial por el nuevo coronavirus constituye una emergencia de salud pública de importancia internacional. La razón principal de esta declaración no es lo que está ocurriendo en China, sino lo que está ocurriendo en otros países" (Director General OMS. Comité de Emergencia).

Durante ese periodo, la comunicación sobre la propagación del COVID-19 adoptó múltiples formas sociales, sea bajo la forma de peligro (como se observó, por ejemplo, en aquellas consideraciones inespecíficas que atribuían su mal a los hábitos higiénicos o alimenticios de las primeras poblaciones afectadas), sea bajo la forma de riesgo, como se observó por caso en su minimización aludiendo, por ejemplo, a su relativa baja letalidad frente a otras epidemias conocidas, y la necesidad de enfrentarla respetando las medidas sanitarias. De esta manera, en un primer momento, la amenaza de la pandemia osciló fuertemente entre ser considerada como un riesgo o un peligro. Este escenario tuvo una diversa aceptación, pero cambió abruptamente cuando la epidemia empezó rápidamente a traspasar fronteras, globalizándose, hasta tener que ser declarada como una efectiva 
"pandemia". Este es un punto de inflexión en la elaboración social de la amenaza y da paso a una segunda fase.

A partir de allí, el SARS-CoV-2 adopta la forma de riesgo para la sociedad mundial: el virus ya no será considerado un peligro, sino un riesgo; su propagación ya no será un suceso natural o providencial, externo a la sociedad o propio de hábitos de poblaciones lejanas, sino que su propagación y efectos serán atribuidos a las decisiones de medidas, mejores o peores, que se toman para enfrentarla. La observación y evaluación de las políticas de contención de la pandemia dejan un lugar para que su amenaza adquiera una nueva elaboración social. Específicamente, una paulatina aceptación de la parte oscura de los riesgos, por ejemplo, una aceptación condicionada de la expectativa del descubrimiento y producción de fármacos para tratar a los afectados y a potenciales contagiados.

La incertidumbre indeterminada de las primeras fases pierde su indeterminación y se fija a una expectativa que refiere a la capacidad de respuesta de la sociedad. Lo anterior no inhibe la preocupación pública que acompaña a la medición de los casos y la divulgación de los estragos, pero sí se abre paso a un escenario porvenir y a la necesidad de medidas, más allá de las sanitarias, que lo anticipen. La imagen de una "nueva normalidad" y de su gradual implementación, se empieza a combinar con la idea de "rescatar" uno de los primeros sistemas sociales afectados por la pandemia: la economía. Mientras que inicialmente todo lo social podía abandonarse para proteger la salud, sin descartar esa pretensión, aparecen otros temas marcados como urgentes, cuya desatención ampliaría el espectro de riesgos propios de la pandemia. Próximamente, la evaluación política de las medidas sanitarias, y luego de las económicas, empezará a ganar su espacio en la comunicación pública. Para todo ello habrá mucho tiempo, pues la "nueva normalidad" será paulatina, implicará retrocesos y, en suma, durará un largo tiempo. La distensión actual, en consecuencia, diversifica la incertidumbre y pone nuevas referencias a los contenidos que se marcan con la oscilación de las atribuciones a riesgos o a peligros, y constituyen el núcleo de la incertidumbre que subsiste ante la pandemia.

En este escenario, nuestra tesis es que algunas de las fuentes de estas nuevas incertidumbres podrían abordarse y corregirse al menos parcialmente mediante la aplicación de herramientas de las ciencias sociales de orientación sistémica, las que han mostrado eficacia a la hora de complejizar y modelar escenarios sociales. Así lo demuestran diversas investigaciones en torno a las crisis (Mascareño. Controversies in social-ecological systems), el riesgo ecológico y el cambio climático (Urquiza y Morales. La observación del problema ambiental en un contexto de diferenciación funcional), los sistemas de protesta (Estrada. Sistemas de protesta), la sociedad mundial (Stichweh. En torno a la génesis de la sociedad mundial), la arena pública (Nassehi. Der soziologische Diskurs der Moderne), lo popular (Stäheli. The popular in the political system), la exclusión y la desigualdad (Cadenas. La desigualdad de la sociedad, Robles Contramodernidad y desigualdad social), el medio digital (Marton. Self-referential technology and the growth of information), entre otros ejemplos a destacar.

Desde la perspectiva sistémica, las posibilidades con que se cuenta en la sociedad para enfrentar la pandemia tienen que ver, tanto con las condicionalidades de cada uno de sus componentes, como con el conjunto del que forman parte. Identificarlas puede ser su aporte. Con ese propósito recurrimos a la teoría de la diferenciación funcional y a su comprensión de la complejidad de la sociedad actual. Siguiendo a Niklas Luhmann "entendemos a la sociedad moderna como funcionalmente diferenciada" (Luhmann 2007:589). Esta línea explicativa tiene una larga tradición 
y ha acompañado, con diversas variaciones, a la observación sociológica y antropológica con que se explica el advenimiento de la época moderna. La selección desarrollada por Luhmann se debe a que éste la elaboró en un programa teórico cuyo nivel de abstracción le entrega la cobertura transdisciplinaria requerida por nuestro objeto de análisis.

\section{Características sistémicas de la sociedad que deben distinguirse para enfrentar la actual pandemia}

Desde la teoría luhmanniana de la diferenciación funcional se considera a la sociedad como una entidad plenamente mundializada. Se destaca que su actual conformación admite diferenciaciones internas, entre las cuales, las que más importan, toman la forma de sistemas sociales especializados, donde "cada sistema funcional está diferenciado para cumplir una función específica" (Luhmann 2007:591). Desde esa comprensión se explicaría por qué los actuales desafíos que impone la pandemia, hasta ahora, no han podido responderse con decisiones y acciones unitarias.

De hecho, observamos cómo varían las perspectivas que se toman en cuenta para interpretar "los hechos", para recomendar "las acciones" y para decidir "las medidas". Ello se debería a que "la diferenciación funcional -como forma de diferenciación de la sociedad- enfatiza la desigualdad de los sistemas de función" (Luhmann 2007:591). En algunos casos priman las consideraciones políticas, en otras las sanitarias o las económicas o jurídicas, o, las más de las veces, en combinaciones variables de varias o de todas ellas. En cualquier caso, todas se modifican dinámicamente a medida que se suceden $\mathrm{y}$, eventualmente, se agregan con nuevos acontecimientos.

Como se aprecia, las diferencias destacadas no son geográficas, tampoco son demográficas ni responden a divisiones entre países, sino que son diferenciaciones entre los componentes sistémicos de la sociedad global, tales como la ciencia, la medicina, la política, la economía o el derecho. Así, ante la crisis provocada por el virus cada uno de estos sistemas reacciona condicionado por las determinaciones estructurales asociadas a sus autonomías, y, recién desde allí, se conforman y/o se diseñan y se toman decisiones. De la misma manera se juzgan las decisiones que se toman en los otros sistemas. En ese modo de operar se encuentran las barreras más importantes que enfrenta la colaboración global requerida en estos tiempos, pues la perfecta interdependencia de los componentes de la sociedad, una sin roce alguno, simplemente no es posible. Por el contrario, los modos más corrientes de relacionarse son las contradicciones y los conflictos.

Como señala Luhmann "los sistemas funcionales generan tiempos particulares y desigualdades que ya no pueden coordinarse societalmente" (Luhmann 2007:609). En esta crisis, la actual configuración sistémica de la sociedad se ejemplifica constatando cómo las actividades científicas operan con sus habituales procedimientos, cuyos resultados dependen de procesos de indagación metódicos, graduales y acumulativos (con gran consumo de tiempo). El propio autor se adelantó al afirmar que "con perspectivas de financiamiento se puede tentar, irritar, pero no aducir ninguna prueba científica" (Luhmann 2007:604).

Otro tanto sucede en la medicina que se vuelca a atender la enfermedad de los cuerpos infectados y a generar salud en ellos, aplicando para lograrlo sus propios criterios y formas de entender (en este caso los tiempos se vuelven extremadamente limitados). Lo mismo ocurre en la economía, que debe mantener flujos ininterrumpidos de operaciones asociadas a las cadenas de pagos para producir y distribuir los insumos requeridos (siempre escasos) para enfrentar la emergencia 
sanitaria. En forma equivalente observamos al derecho produciendo normas y notificando penalizaciones para delimitar una convivencia social a derecho (más allá de que acciones se consideren atrasadas o irónicamente inconstitucionales). Por su parte, la política, en medio de las mayores dificultades y en todos los países conscientes del problema, se esfuerza por producir y sostener decisiones vinculantes extraordinarias a través de recursos gubernamentales de administración pública ordinaria (tiempo dedicado a dilatar refinadamente la referencia a la fuerza legítima o a quebrarse y emplearla efectivamente). En ese último plano se aprecian las oportunidades que la pandemia le ha planteado a los partidos gobernantes a propósito de articular estrategias conjuntas con los opositores. En este sentido, los programas democráticos muestran mucha plasticidad ante los diversos escenarios, quizás excesiva para los valores "democráticos", ya que es igualmente democrática la unidad nacional como la polarización de la distinción gobierno/oposición en escenarios como el que hoy se presenta en muchos países de nuestro continente.

Esto nos conduce al siguiente panorama: tanto la capacidad de respuesta de la sociedad como su contracara, la dificultad de tales respuestas para volverse convergentes, son igualmente consecuencias de una misma causa: la diferenciación funcional. Este tipo de diferenciación proyecta un "agudo déficit de racionalidad" para "enfrentar los problemas globales" mediante "decisiones integrales". Examinemos esto último.

Damos por descontado que la heterogeneidad, lentitud o incoordinación de las respuestas a la actual crisis pandémica no obedece a la falta de voluntades o a la existencia de intereses ocultos, sino, por sobre todas las razones, a una estructura de la sociedad compuesta por sistemas funcionalmente diferenciados. Esta conformación obedece a procesos sociales que pueden ser observados y cuyo escrutinio permite identificar algunas opciones favorables para las actuales circunstancias.

En el transcurso de su evolución en la sociedad, los diferentes sistemas sociales fueron diferenciándose; así construyeron sus identidades y reforzaron sus autonomías para poder desarrollar con mayor éxito sus operaciones especializadas (piénsese en cómo la religión y la ciencia al separarse profundizan y extienden sus funciones). Pero, simultáneamente, como consecuencia de ello, los sistemas no pueden someterse a los criterios de otros sin afectar sustantivamente su continuidad. No es un asunto de buena voluntad o de la falta de ella, sino de los nuevos márgenes de comprensión e incomprensión generados por las nuevas identidades y autonomías. En este marco, la gestión de riesgos y la toma de decisiones no puede dar por supuesto un continuum entre los medios, fines y valores y, desde allí, sugerir opciones y nuevos ordenamientos para las acciones y las instituciones sociales. En vez de ello, se debe cuestionar las premisas de este razonamiento y enfatizar que, en condiciones de diferenciación funcional, no están dadas las condiciones para ningún continuum universal de los valores o de los fines sociales o humanos.

Esto, aun cuando sus problemas puedan ser de naturaleza global y potencialmente universales, como en el caso de una pandemia y donde los criterios de racionalidad siguen existiendo, pero no en el orden de un urbi et orbi común, sino en una comprensión con premisas forzosamente parciales y múltiples en su lugar de origen (economía, ciencia, salud, política, etcétera), aunque, no por ello, menos globales y universales en su dinámica y extensión. En este sentido, quien observe la actual amenaza, deberá necesariamente tomar en cuenta la co-existencia de múltiples racionalidades. Así pues, el objetivo de producir propuestas convergentes, en condiciones de diferenciación funcional, 
está forzado a seleccionar y, luego, a racionalizar esta selección con nuevas selecciones. La racionalidad no deja de existir en la diferenciación funcional, sino que adopta el formato de la racionalidad más bien estratégica y, por tanto, limitada. De hecho, quien asuma los viejos modelos de una racionalidad simplificada medios/fines/valores universales, encontrará un mundo de peligros en la progresión de la pandemia, en cambio quien mude sus premisas a la racionalidad limitada y global será más consciente de los riesgos. Este último modelo ofrece un mejor panorama para eventuales sinergias.

Algunos ejemplos pueden ser ilustrativos de la condición polimórfica y diferenciada de la sociedad contemporánea. Si la actividad de la ciencia, apremiada por encontrar algún remedio, descuida sus procedimientos investigativos inclinándose al puro negocio o a responder a la presión política, en el acto dejaría de ser lo que es. La sociedad no podría esperar nada de ella. Algo equivalente ocurre con la política de Estado: dada la actual pluralidad de intereses, si sometiera la deliberación a la presión de una plena participación, se recargaría con discusiones de dudosa representatividad y, lo más importante, sus decisiones no serían las oportunas. Por su parte, para mantener su ecuanimidad en la administración de la justicia y hacerla sentir justa, y por tanto respetable, el derecho no puede atiborrarse de normas de excepción sin crear de iure una nueva normalidad de facto. La medicina no puede (en nombre de la falta de terapias específicas y de la limitada eficacia de los remedios implementados) abandonar los criterios clínicos previamente ensayados y testeados para volcarse hacia la práctica de formas de sanación no convencionales sin dejar de ser medicina (más allá de los resultados que obtuviera). Finalmente, las actividades económicas no pueden paralizarse sin tomar los resguardos para asegurar la circulación de los medios de pago y así evitar la caída vertical de sus operaciones.

Ciertamente, en situaciones de crisis los sistemas modifican sus programas habituales de funcionamiento y pueden variarse las formas en que regulan sus actividades, pero tales cambios no pueden afectarles en lo esencial. La medicina, la ciencia, la economía, la política o el derecho perseveran como tales y no pueden convertirse por ellos mismos en otra cosa. Esto se ahonda, además, por el hecho de requerirse mutuamente para la mantención de sus viabilidades.

Esta descripción ejemplifica el gran problema de la complejidad de la sociedad: si bien cada uno de sus componentes puede orientarse para responder a la pandemia, solo puede hacerlo mediante sus propias operaciones. En su aplicación, estas racionalidades altamente específicas y limitadas implican numerosos conflictos, desconciertos y mucha decepción en la ciudadanía mundial, a la que solo le resta confiarse en el ejercicio de la voluntad y del "sentido común". Para estos ejercicios, las condicionantes estructurales no resultan evidentes.

La invisibilidad de las estructuras subyacentes a los procesos sociales que hemos mencionado se debe, en parte, a que los efectos de la diferenciación funcional no solo se expresan en las formas especializadas del operar de los sistemas sociales. Aunque "los seres humanos deben conceptuarse como entorno del sistema de la sociedad" (Luhmann 2007:590), las formas más visibles de los sistemas están representadas por sus eventuales voceros. En estas personificaciones de los sistemas sociales, desempeñadas por seres humanos investidos de roles sociales, puede observarse sin mayor esfuerzo la fuerza de guía que tienen en ellas los intereses, especialmente aquellos que persiguen mejores posiciones y chances incrementando prestigio, autoridad y/o medios de pago. Así las estructuras se personifican y se colman de atribuciones psicológicas (por ejemplo, buena o mala voluntad, agendas ocultas, etcétera) y de rasgos biográficos. Esto último, especialmente por 
sus vetas espectaculares y disfuncionales, es muy apetecido por los medios de comunicación que son, a su vez, otro sistema diferenciado en la sociedad y que, como tal, requiere de informaciones con valor noticioso. Es así como, en su búsqueda de primicias y novedades, los medios no pueden evitar privilegiar el sensacionalismo y parasitar de los acontecimientos excepcionales y/o las polémicas con sus "bajadas", "cuñas" y titulares. Gracias a esos contenidos comunicativos refuerzan y aseguran su continuidad.

Vista desde una posición más estructural, la interpelación más contundente que la amenaza del COVID-19 le plantea a la diferenciación funcional, y de allí a la sociedad en su conjunto, es la siguiente: ¿cuán probable es que componentes sistémicos de la sociedad ya diferenciados, puedan acoplarse ante un problema global y enfrentarlo de manera integrada? La respuesta, asumida la teoría de la diferenciación funcional, es que eso es improbable, y que tampoco es probable que las respuestas ofrecidas por esa hipotética unificación/integración fueran mejores. La sociedad ya no podría contar, dada su complejidad, con una sola racionalidad. El desafío es, entonces, cómo podrían hacerse recomendaciones frente a la actual emergencia que consideren las posibilidades de la sociedad y que vayan en dirección de hacer probable lo improbable. Entre todas las incertezas un camino para ello consiste en evitar recomendaciones imposibles de implementar.

Una respuesta a lo dicho arriba, también teórica, es intentar compatibilizar algunas prestaciones de los sistemas diferenciados aprovechando que su autonomía no es ni total ni absoluta. La posibilidad es evidente: en los sistemas no rige la autarquía, dependen del entorno que les entrega sus posibilidades. Esto es, cada sistema "presupone que las demás funciones se cumplen en otro lugar" (Luhmann 2007:596). Dicho más precisamente, los sistemas de la sociedad en sus operaciones son autopoiéticos, pero necesitan de condiciones que no se auto-proveen. Como señaló Nassehi: "la autonomización operativa de las funciones no significa de ninguna manera el total desacoplamiento de los sistemas funcionales" (Nassehi 2011:22).

Para mantener su existencia, todos los sistemas sociales requieren de posibilidades que son abastecidas en sus interdependencias con múltiples prestaciones u outputs de otros sistemas, es decir, entre los sistemas diferenciados hay "dependencias recíprocas" (Luhmann 2007:601). Estas interdependencias que ocurren a nivel de sus estructuras dan cuenta de sus aperturas al entorno. Así, es evidente que para enfrentar la pandemia se requiere invertir mucho dinero en la investigación científica; que la política necesita del concurso de leyes para restringir libertad de movimiento y aplanar la curva de contagios; que los medios no pueden alarmar de cualquier modo sin ser penalizados; que la medicina requiere de conocimientos certificados y validados con evidencias científicas, etcétera. Es en ese plano que pueden explorarse algunas posibilidades para intervenir y alcanzar objetivos determinados dentro de las actuales circunstancias. Estas posibilidades las entregan los sistemas organizacionales. Como indica Luhmann, "las organizaciones posibilitan interdependencias sociales compatibles con la autopoiesis y con la clausura operativa de los sistemas funcionales" (Luhmann 2007:657). Desde esa última consideración, nos orientaremos al propósito de ensayar con algunas recomendaciones, preliminares y tentativas, derivadas desde una comprensión sistémica.

\section{Recomendaciones para diseños organizacionales sinérgicos ante crisis globales}

El principio básico de una recomendación orientada a la sociedad global es contar con un adecuado diagnóstico. Las observaciones que lo producen deben seleccionarse cuidadosamente: no se puede 
esperar tomar en cuenta a todos y cada uno de los componentes de la sociedad. Dada la complejidad alcanzada en su forma contemporánea, la gran mayoría de sus expresiones permanecerán sin registrarse, pendientes o ignoradas.

El foco estratégico que sustenta nuestras recomendaciones es el de indagar en los criterios con los cuales se produce y procesa la información que se difunde sobre la pandemia, cómo se comprende y entre quiénes se produce y con qué metodologías se acuerdan las políticas para su afrontamiento. Especial atención debe tenerse en los sistemas científico, político y económico, los que se vinculan directamente con medidas socio-sanitarias, especialmente de aquellas que tienen cobertura mundial. En este punto debe advertirse que "las organizaciones son los únicos sistemas sociales que pueden comunicarse con su entorno" (Luhmann 2007:668). Bajo ese marco colocamos en primeros planos de atención a las organizaciones en las cuáles parece descargarse la ejecución de las operaciones de los sistemas de la sociedad.

En primera instancia, nuestra propuesta destaca las organizaciones que vinculan sus decisiones con referencias a los sistemas de la ciencia, el sanitario, el político y el económico. Este orden tiene el propósito de identificar propuestas vinculantes que se orientan a la contención de la epidemia y, en general, a las acciones actuales y futuras que tengan tal objetivo.

Nos concentramos en las organizaciones, pues con ellas son enfrentadas las incertidumbres sociales asociadas al COVID-19, y el procesamiento de riesgos y peligros es procesado gracias a este tipo de sistemas al nivel de las decisiones y con la prosecución de objetivos. La teoría señala que las dinámicas diferenciadas de los sistemas parciales de la sociedad están en el entorno de las organizaciones (una empresa farmacéutica tiene por entorno, por ejemplo, a la economía y a la ciencia). Este modo de observar permite apreciar cómo la finalidad de una organización cualquiera está acoplada a los sistemas de su entorno, pero sus operaciones básicas, es decir, sus decisiones, no se corresponden forzosamente con las esperadas por los sistemas que le sirven de referencia. Una organización puede verse favorecida en contextos funcionales negativos o verse perjudicada en contextos positivos (por ejemplo, si los emprendimientos levantados durante la crisis no son demandados una vez superada, por caso la fabricación a gran escala de respiradores artificiales). Aunque el margen de acción de las organizaciones es acotado, sus posibilidades de irritar y afectar sus entornos y de cambiar el curso de las cosas son mayores, pues disponen de numerosas posibilidades para abordar la incertidumbre a través la toma de sus decisiones, su evaluación interna y de la formulación de objetivos emergentes.

Desde esta perspectiva, el abordaje de las formas de riesgo del COVID-19 coloca a las organizaciones en una posición estratégica, pues cuentan con la posibilidad concreta de incorporar con celeridad la contención de la pandemia entre sus propósitos, aunque deban decidir bajo la dependencia de prestaciones económicas y políticas, por ejemplo. Esa dependencia de condiciones que no pueden autoabastecerse, permite identificar obstáculos que deben removerse para facilitar el cumplimiento de sus fines.

Por ejemplo, las organizaciones que tienen por misión afrontar consecuencias de la pandemia requieren que se proteja efectivamente la circulación global de los conocimientos e informaciones que les son pertinentes (resultados de ensayos, estadísticas, etcétera), que se limiten las resistencias políticas (nacionalismos, "secretos de Estado") y económicas (las carreras por licencias y patentes). Un ejemplo alentador de lo anterior fue la temprana divulgación del genoma del virus por parte de 
China (para el caso un obstáculo removido desde la política). La desconsideración de las condiciones requeridas por las organizaciones, también, ha tenido ejemplos negativos, por ejemplo, se sospecha de una demora (políticamente motivada) en dar cuenta de la epidemia o, recientemente, para priorizar la continuidad de las actividades económicas, estar adelantando una vuelta a la "normalidad" sesgando las informaciones.

Uno de los principales obstáculos que puede estar limitando o retrasando las respuestas sanitarias a la pandemia, tiene relación con las condiciones que presuponen las organizaciones dedicadas a su investigación. Estas entidades disponen sus instalaciones para producir conocimientos, pero requieren asegurar el abastecimiento de sus condiciones. Así requieren obtener rendimientos por sus descubrimientos. Enfrentadas al "dilema del prisionero", ante la búsqueda de recursos, pueden optar a un juego de "suma cero". Se trata de una estrategia auto-asumida por algunas organizaciones, sin embargo, desde una mirada global puede advertírseles que en cualquier momento puede haber descubrimientos independientes y las pérdidas, que pueden ser de todo tipo, por haber retenido información, les serán enormes. Salta a la vista que la opción más recomendable para ellas es la colaboración, sobre todo la internacional. Pero para esto se requieren marcos legales claros, es decir una juricidad ad hoc, que únicamente puede ser producida por prestaciones derivadas del derecho. Tomando en cuenta lo anterior, todo laboratorio, sea privado, universitario o estatal, es considerado como una organización en cualquier lugar del planeta donde esté radicado, en la medida en que tenga en cuenta la emergencia sanitaria como centro de su atención y tome decisiones orientadas hacia ella. Mandantes y localizaciones, más allá de sus motivaciones, son equivalentes funcionales. Vale aquí el proverbio que indica que no importa tanto el color del gato si lo que se quiere es cazar ratones.

El problema práctico es concentrarse en detectar cómo se pueden articular y, a la vez, resguardar los intereses de organizaciones que se guían por propósitos similares, aunque con motivos divergentes (económicos, humanitarios o políticos). Para ello se recomienda depositar la convergencia en la salvaguarda de un objetivo central: la obtención de un tratamiento para el coronavirus en los plazos más cortos posibles, ese tratamiento puede ser preventivo para reducir o eliminar la transmisión del virus SARS-CoV-2 (equivalente a las sinergias ciencia-medicina-políticaeconomía contra el brote de poliomielitis), o bien terapéutico-educativo-comunicacional para reducir o mitigar los decesos en el tratamiento clínico (equivalente a las sinergias contra el VIH/SIDA).

Las indicaciones anteriores, una vez desplegadas, son obvias. El problema no solamente son los obstáculos que dificultan, sino también las barreras cognitivas que impiden considerarlas debidamente, es decir, comprenderlas y producir sobre esa base decisiones o acciones. Se trata de poder tomar en cuenta los obstáculos para tomar en cuenta los obstáculos. Para ello se propone nuestro plano teórico de observación. Específicamente, la teoría de la diferenciación funcional, que permite orientarse en lo que debe tomarse en cuenta para dar cuenta de cómo se observa la pandemia ("observación de observaciones"), estimar sus alcances y variaciones para luego, a la luz de su cálculo, indicar los puntos ciegos que se revelan desde considerar un escrutinio de parcialidades.

En esa dirección pueden proponerse diseños organizacionales que faciliten observaciones mutuas y que, mediante ellas, posibiliten y hasta estimulen la generación y entrega de ventajas sinérgicas (por ejemplo, con alguna variante de las formas matriciales). Para mejorar estas posibilidades existen 
prototipos, por ejemplo, los equipos transdisciplinarios o los comités intersectoriales. Lo novedoso de la recomendación es considerar la diferenciación funcional en su composición, destacar los rendimientos de tal opción y prever las dificultades que conlleva gestionar y administrar grandes volúmenes de informaciones de diverso tipo. Para esto último el incremento de la variedad interna de las organizaciones favorece las condiciones requeridas para trabajar, desde distintos ángulos, para un mismo objetivo central ante la emergencia.

También pueden promoverse los intercambios de perspectivas entre los sistemas que se encuentran involucrados (político, económico, científico, sanitario, etcétera) con el tema de la pandemia y, desde allí, destacar puntos comunes evitando, hasta donde sea posible, que comunicaciones unilaterales generen decisiones excluyentes. Se dispone de trabajos teóricos y prácticos sobre trabajos de concertación grupal que consideran las interlocuciones sistémicas y sus modos de afrontarlas, entre otros destacados que merecen ser mencionados encontramos la propuesta de $A$. Urquiza (Metálogo como herramienta de colaboración transdisciplinaria), de H. Willke (Formas de autoorientación de la sociedad) y de A. Mascareño (Sociología de la intervención). El foco es atender en qué condiciones y qué resultados pueden producirse desde esos intercambios, como también identificar en qué punto estos pueden atentar contra el funcionamiento organizacional (lentificarlo en exceso, por ejemplo).

Recordemos que las determinaciones sistémicas (sin considerar sus precondiciones) se encuentran entre las principales ventajas para acelerar la generación de resultados eficientes y útiles para reforzar la colaboración, pero que también se encuentran, al mismo tiempo, entre las principales limitaciones para lograrla primero y para mantenerla después. Esto se debe a que afectan la comprensión y abordaje de problemas complejos: la especialización tiene aquí la forma de una desventaja. Se trata, como se insiste, que cada sistema observa a la pandemia desde su referencia y, desde allí, orienta sus acciones. Este obstáculo no es antojadizo, sino que está comprometido en las racionalidades que lo configuran. Por ello, reiteramos, deben identificarse las condicionalidades de los sistemas que se necesitan relacionar y, desde ese reconocimiento, aunque sea limitado, explorar las conectividades sinérgicamente más favorables. Se trata, en otras palabras, de al momento de proyectar y procurar acoplarlos, considerar sus lógicas ante el objetivo perseguido o el problema planteado. Esta perspectiva se respalda en el sentido común, aunque despojándolo de su ilusión idealista: ante situaciones críticas "conózcanse y produzcan los acuerdos posibles". El desafío de "conocerse" consiste en identificar las lógicas y códigos que configuran, mantienen y estructuran al otro sistema en cuanto tal.

Llegado este punto cabe subrayar que, para los diseños organizacionales recomendados, es de crucial importancia la delimitación de las expectativas que se les extienden y la estilización de ellas con la mayor precisión posible, pues, en ese plano (de las expectativas), se forma el horizonte de las comunicaciones, como así también los marcadores que dan lugar a sus evaluaciones. Específicamente es prioritario que la continuidad del trabajo organizacional cuente con ejes y parámetros de factibilidad fijados estrechamente a los objetivos buscados. 


\section{Comentarios finales}

Hemos intentado demostrar que la perspectiva sistémica, especialmente en la versión sociológica desplegada por Niklas Luhmann, puede contribuir en forma efectiva a complementar la comprensión de los efectos de la pandemia en la sociedad con un razonamiento crítico y alternativo. Para ello hemos vinculado la diferenciación funcional con las posibilidades que tienen las organizaciones para sincronizar las prestaciones sistémicas.

En términos específicos, las aplicaciones de esta teoría se orientan a favorecer la construcción de sistemas organizacionales donde se articule y produzca la mayor variedad (no la mayor cantidad) de observaciones con la expectativa que, de sus encuentros, surjan efectos sinérgicos (nuevas ideas, nuevas relaciones, nuevas propuestas). Los organismos internacionales abocados a temas sanitarios, y sus equivalentes de coberturas nacionales o regionales, podrían ser los puntos de partida para ejercitar estas propuestas. La creación y el diseño de observatorios independientes, agencias de normas técnicas o de agencias acreditadoras, que cuenten con una cobertura global, se presenta también como otra buena alternativa.

En síntesis, bajo el supuesto que enfrentar la actual crisis sanitaria requiere esfuerzos colaborativos, la intervención sistémica parte del reconocimiento tanto de la complejidad de la sociedad como de la complejidad involucrada en la pandemia. Su estrategia es favorecer acoplamientos, mediados organizacionalmente, entre sus componentes sistémicos los que, por su misma condición, solo pueden abordar parcialmente los problemas globales de la sociedad. Para lo anterior, destacamos la utilización de las capacidades instrumentales y flexibilidad de los sistemas organizacionales, los que, a diferencia de lo que ocurre en otros tipos de sistemas sociales, tienen las mejores chances para autoevaluarse y autocorregirse en tiempos acotados.

Aunque no ha sido desarrollado en las líneas precedentes, se advierte que las organizaciones sociosanitarias que incorporen diseños que favorezcan la sinergia, también deberán lidiar en una sociedad global con amplios márgenes de exclusión social. Se enfrentarán, por ello, a situaciones doblemente problemáticas. Materia que requiere especial atención, pero que requeriría un tratamiento en detalle que no corresponde hacerlo aquí.

Por último, pero no en orden de importancia, pensando en los cultores de las perspectivas sistémicas que no quieren arriesgarse con orientaciones para decisiones prácticas a nivel organizacional, ellos podrían proyectar sus observaciones a escenarios post-pandemia. Las actuales respuestas a la crisis pueden tratarse como experimentos cruciales atendiendo a las decisiones que se apreciaron asociadas a sus mejores (o peores) resultados. Si bien nuestro comentario se ha posicionado desde la referencia de la sociedad mundial, sus alcances no se limitan a ella. La micropolítica que se expresa en organizaciones, grupos y localidades también puede, y debería, ser documentada sistemáticamente aplicando los procedimientos de la investigación social cualitativa. Acontecimientos similares se repetirán y deberán recordarse para afrontar futuras amenazas globales. Su memoria reduciría su pura imagen de peligros superados y para poder procesarlas como riesgos siempre latentes. La idea es que sus registros sistemáticos de la complejidad de la sociedad, validados con sus procedimientos científicos, podrían incorporarse al debate sobre los "porvenires" deseables para nuestras futuras formas de convivencia en el planeta. 


\section{Bibliografía}

Luhmann, N. (2007). La sociedad de la sociedad. Herder.

Maturana, H. (2009). Fundamentos biológicos del conocimiento. Editorial Universidad Iberoamericana.

Nassehi, A. (2011). La teoría de la diferenciación funcional en el horizonte de sus críticas. Revista Mad, 24, 1-29. https://doi.org/10.5354/0718-0527.2011.13529

Recibido el 20 May 2020

Aceptado el 12 Jul 2020 